\title{
Are Bacterial Growth and/or Chemotaxis Increased by Filler Injections? Implications for the Pathogenesis and Treatment of Filler-Related Granulomas
}

\author{
Jaume Alijotas-Reig ${ }^{a, d} \quad$ Francesc Miró-Mur ${ }^{a} \quad$ Irene Planells-Romeu ${ }^{b, d}$ \\ Natalia Garcia-Aranda ${ }^{a}$ Victor Garcia-Gimenez ${ }^{a, c} \quad$ Miquel Vilardell-Tarrés ${ }^{a}$ \\ a Systemic Autoimmune Disease Unit, Department of Internal Medicine I, Aging Basic Research Group, Molecular \\ Biology and Biochemistry Research Center for Nanomedicine, CIBBIM-Nanomedicine, Vall Hebron University \\ Hospital, ${ }^{b}$ Microbiology Department, Vall Hebron University Hospital, ' $E u r o p a$ Medical Center, and ${ }^{\text {d Universitat }}$ \\ Autonoma, Barcelona, Spain
}

\section{Key Words}

Bacterial infection • Chemotaxis · Filler injections •

Granulomas · Treatment

\begin{abstract}
Background: As microbial agents have been associated with late adverse effects related to fillers antibiotic treatment has been envisaged. Objective: To determine whether biomaterials favor bacterial growth and/or attract bacteria. Methods: Hyaluronic acid, semi-permanent fillers, such as calcium hydroxylapatite, and permanent fillers, such as polyalkylimide/ polyacrylamide, were used. Experiments were performed with Escherichia coli, strain $\mathrm{HVH}-U 47$. Bacteria were transferred to Sven-Gard agar to test mobility. Striae of this bacterial strain with a MacFarland 1 turbulence pattern were seeded from a spot of inoculated biomaterial using Müller-Hinton medium. The chemoattractive properties of the biomaterials were analyzed 10 days after inoculation. Bacterial growth over the biomaterial and in-depth growth were assessed as well. Results: Semi-permanent fillers did not stimulate bacterial growth but they allowed bacterial colonization over the filler. Permanent acrylic compounds neither presented
\end{abstract}

chemoattractant properties nor showed bacterial growth over the biomaterial. Similar results were obtained when performing in-depth cultures. Conclusions: Permanent and semi-permanent fillers did not facilitate bacterial growth when flagellated E. coli HVH-U47 was used. Our results do not argue in favor of antibiotics as the mainstay of therapy in late granulomas related to permanent fillers. In the case of resorbable/semi-permanent fillers, more studies are needed before recommending antibiotic therapy.

Copyright $\odot 2010$ S. Karger AG, Basel

\section{Introduction}

An increasing number of persons seek medical solutions for aged skin or purely aesthetic and cosmetic indications. Several biomaterials have been developed as dermal fillers to satisfy these needs $[1,2]$, and also to provide alternative treatments in other medical areas, such as nanomedicine, ophthalmology, traumatology and urology $[3,4]$. Currently, physicians use many different types of dermal fillers, such as non-permanent, permanent, reversible or nonreversible biomaterials. Although manu-

\section{KARGER}

Fax +4161306 1234 E-Mail karger@karger.ch www.karger.com
(ㄷ) 2010 S. Karger AG, Basel

$1018-8665 / 10 / 2214-0356 \$ 26.00 / 0$

Accessible online at:

www.karger.com/drm
Jaume Alijotas-Reig, MD, PhD

Josep $\mathrm{M}^{\mathrm{a}}$ de Segarra, 2-F

ES-08190 Sant Cugat del Vallés, Barcelona (Spain)

Tel. +34 93489 4194, Fax +34934893039

E-Mail jalijotase@vhebronet.net 
facturers and reported data claim that fillers are nontoxic, nonimmunogenic and that complications are very uncommon $[5,6]$, unwanted side effects do occur with all available compounds $[1,7-9]$. Thus, two notions are lacking in the usual classification of fillers: long-term safety and reversibility of side effects.

The mechanisms underlying the activation of the immune system and leading to chronic granuloma formation are not yet clarified. Granulomatous reactions may be triggered by various factors, notably biomaterials. Sarcoidosis and sarcoid granuloma could be the paradigm of the relationship between persistent antigens (self or nonself), such as fillers, and immune response. Continuous antigens may provoke CD4+Th1 lymphocyte activation with subsequent cytokine-related macrophage recruitment. This process ends with granuloma formation. The levels of T-cell-derived proinflammatory cytokines mainly interleukin (IL) 2, IL-12 and $\gamma$-interferon - are increasing in the involved tissue but normal in peripheral blood or cell cultures. This immune Th1 lymphocyte hyperactivity parallels an inadequate suppressor arm of the immune response. Therefore, a chronic local or systemic immune-mediated inflammatory disorder develops $[10,11]$.

Some late side effects of fillers have been related to infections (bronchitis, pharyngitis, flu and pneumonia), suggesting that bacteria and viruses might also be implicated $[12,13]$. In this connection, Christensen et al. [14] reported that local bacterial growth may be the cause of some of these granulomatous responses. Furthermore, the relationship between bacteria and viruses and inflammatory immune-mediated disorders and autoimmune diseases (i.e. systemic lupus erythematosus, antiphospholipid syndrome, systemic vasculitis or, sarcoidosis) is still under discussion $[10,15,16]$.

Microbial agents can induce immune-mediated diseases by a variety of mechanisms, i.e. protein-induced polyclonal activation on lymphocyte subsets, T-cell-stimulated bacterial-induced cytokine imbalance with upregulated Th1 subsets, thereby increasing selected expression of major histocompatibility complex molecules. Activation of costimulatory molecules, microbial encoding superantigens and molecular mimicry are other diverse mechanisms that might explain the causal relationship between infections and immune dysregulation $[15,17]$.

In the present study, we have analyzed the ability of different biomaterials (dermal fillers) to favor bacterial growth and chemoattraction.

Bacterial Infection and Late Granuloma Related to Dermal Fillers

\section{Subjects and Methods}

\section{Study Subjects}

We have analyzed a total of 193 cases showing late-onset adverse side effects related to implant fillers from January 2001 to September 2008 (fig. 1). After attending and treating a considerable number of cases, we wondered whether bacteria may be implicated as causative or triggering agents of these late-onset adverse effects. These questions also arose when evaluating the results of former in vitro experiments. Blood samples were taken from 110 patients of this cohort. Thereafter, peripheral blood mononuclear cells were obtained according to standard procedures to perform different other studies apart from those mentioned above [11, 18-22].

\section{Biomaterials and Bacterial Strain}

Semi-permanent bioimplants, such as hyaluronic acid (NASHA, Restylane A, Q-Med, Uppsala, Sweden) and calcium hydroxylapatite (Radiesse, BioForm Medical Inc., Sant Mateo, Calif., USA) and permanent fillers, such as polyalkylimide (Bioalcamid, Polymekon, Brindisi, Italy) and polyacrylamide (Aquamid, Contura International, Soeborg, Denmark), were used.

\section{Bacterial Strain}

A special mobile flagellated bacterium, Escherichia coli $\mathrm{HVH}$ U47, was selected as microbial agent. E. coli HVH U47 was obtained and cultured according to standard microbial manipulation protocols.

\section{Chemotaxis Experiments}

In order to test flagellated bacterial mobility, E. coli HVH U47 was transferred to Sven Gard soft agar (glucose, 1 g; yeast extract, $1 \mathrm{~g}$; meat extract, $5 \mathrm{~g}$; tryptic soy broth, $10 \mathrm{~g}$; Bacto Agar, $5 \mathrm{~g}$; distilled water to $1,000 \mathrm{ml} ; \mathrm{pH} 7.6$ ), autoclaved at $110^{\circ} \mathrm{C}$ for $20 \mathrm{~min}$. Striae of E. coli $\mathrm{HVH} U 47$ strain having a turbulence pattern of MacFarland $1\left(3 \times 10^{8} \mathrm{CFU} / \mathrm{ml}\right)[23]$ were seeded at $0.5 \mathrm{~cm}$ from a spot of inoculated biomaterial using Müller-Hinton medium (beef dehydrated infusion, $300 \mathrm{~g}$; Casamino acid, 17,5 g; starch, 1,5 g; Agar, $17 \mathrm{~g}$; distilled water to $1,000 \mathrm{ml}$ ) specific for bacterial mobility detection [24]. In every plate, a specific biomaterial was previously inoculated with the bacterial medium at the following times: $24,48,72 \mathrm{~h}$ and 7 days. The chemoattractant properties of the biomaterials were analyzed after 10 days of bacterial inoculation.

\section{Bacterial Growth Tests}

Growth over biomaterials was tested in plates with MüllerHinton medium; $1 \mathrm{ml}$ of E. coli at MacFarland 1 concentration was seeded. In every plate a surface deposition of each biomaterial was done. Results were taken daily for a period of 10 days. Bacterial in-depth growth tests were also performed. Briefly, $1 \mathrm{ml}$ of $E$. coli at MacFarland 1 concentration was dissolved in $9 \mathrm{ml}$ of brain-heart infusion (calf brain infusion, $7.5 \mathrm{~g}$; beef heart infusion, $10 \mathrm{~g}$; peptone proteose, $10 \mathrm{~g}$; glucose, $2 \mathrm{~g}$; sodium chloride, $5 \mathrm{~g}$; disodium phosphate, $2,5 \mathrm{~g}$; water to $1,000 \mathrm{ml} ; \mathrm{pH}$ adjusted to 7.4). The brain-heart infusion medium was supplemented with $0.1 \%$ agar. E. coli was inoculated when the supplemented brainheart infusion medium was not yet solidified. The inoculated medium was poured over a Petri dish. Five spots of one biomaterial per plate were placed in the middle of the plate, at $3 \mathrm{~mm}$ depth. 
Fig. 1. Flow chart showing the number of patients and type of fillers known or used in our unit.

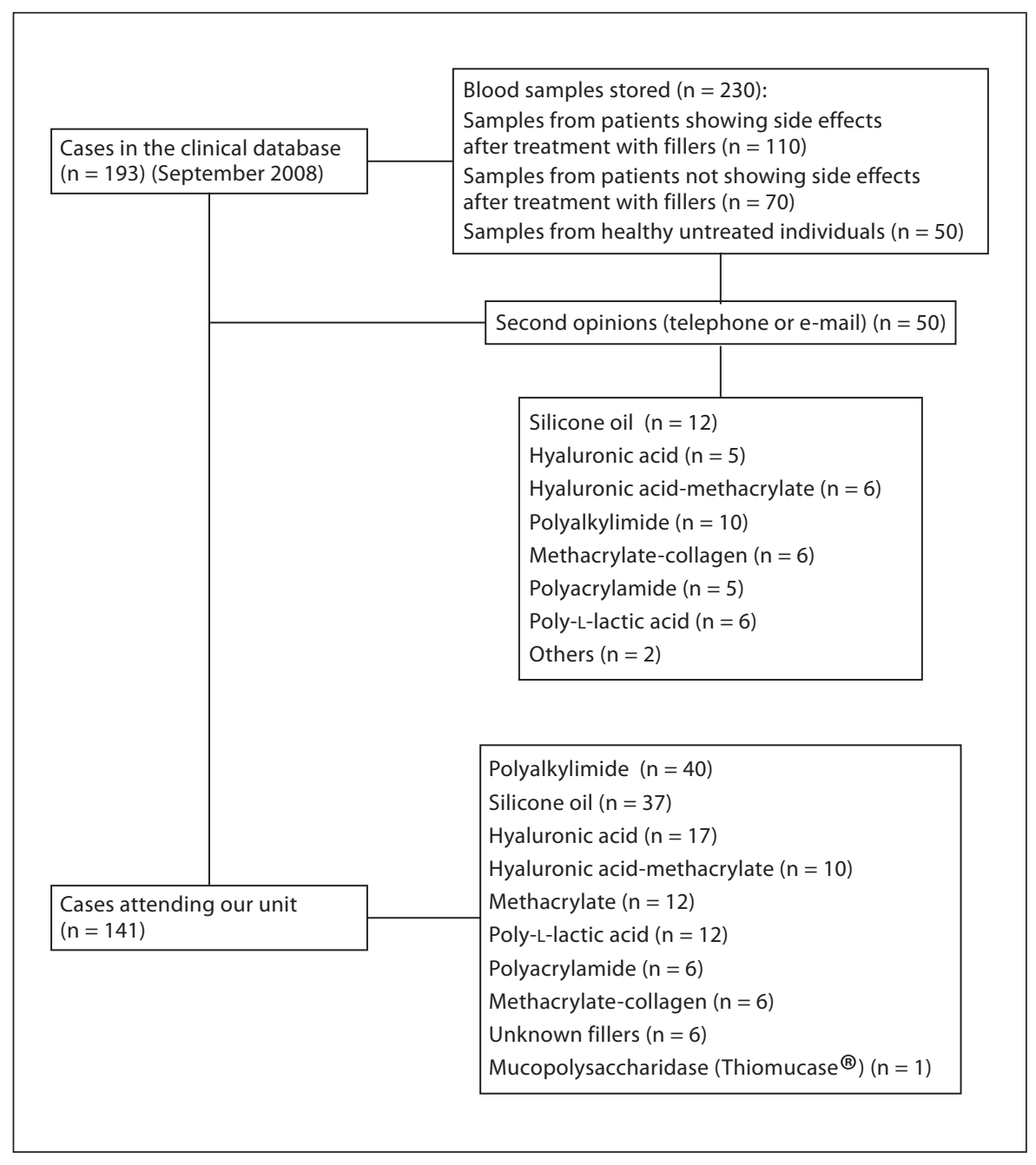

Results were taken daily during 10 days. All experiments were carried out in duplicate.

In order to exclude the possibility of overseeing bacterial growth, bacterial colonization or adherence to fillers when examining the plates simply by eye, we also read them using a magnifying glass (SZH-ILLK, Olympus Optical Co Ltd, Japan) and an inverted microscope (epifluorescence microscope BX71 Olympus Co Ltd.).

\section{Results}

Resorbable, semi-permanent (hyaluronic acid calcium hydroxylapatite) and permanent (polyacrylamide and polyalkylimide), biomaterials with different biochemical and different biophysical properties were analyzed for their ability to favor bacterial growth and activation as depicted above. The four biomaterials used did not show chemoattractant activity towards bacterial growth (fig. 2). However, different bacterial behavior was observed according to the injected filler. A stopping line of growth was detected for acrylamides such as polyalkylimide and polyacrylamide compounds. In contrast, in the case of hyaluronic compounds and calcium hydroxylapatite, bacteria grew and proliferated through the biomaterial. Moreover, bacteria grew easily (fig. 3). Further, bacterial growth around or towards biomaterials was also analyzed by observing proliferation and migration of $E$. coli seeded in a plate containing several spots of injected biomaterials. Figure 3 shows surface colonization of $E$. coli in different plates, each containing a specific biomaterial. None of the described biomaterials exhibited a biological effect, i.e. growth, proliferation or migration of 

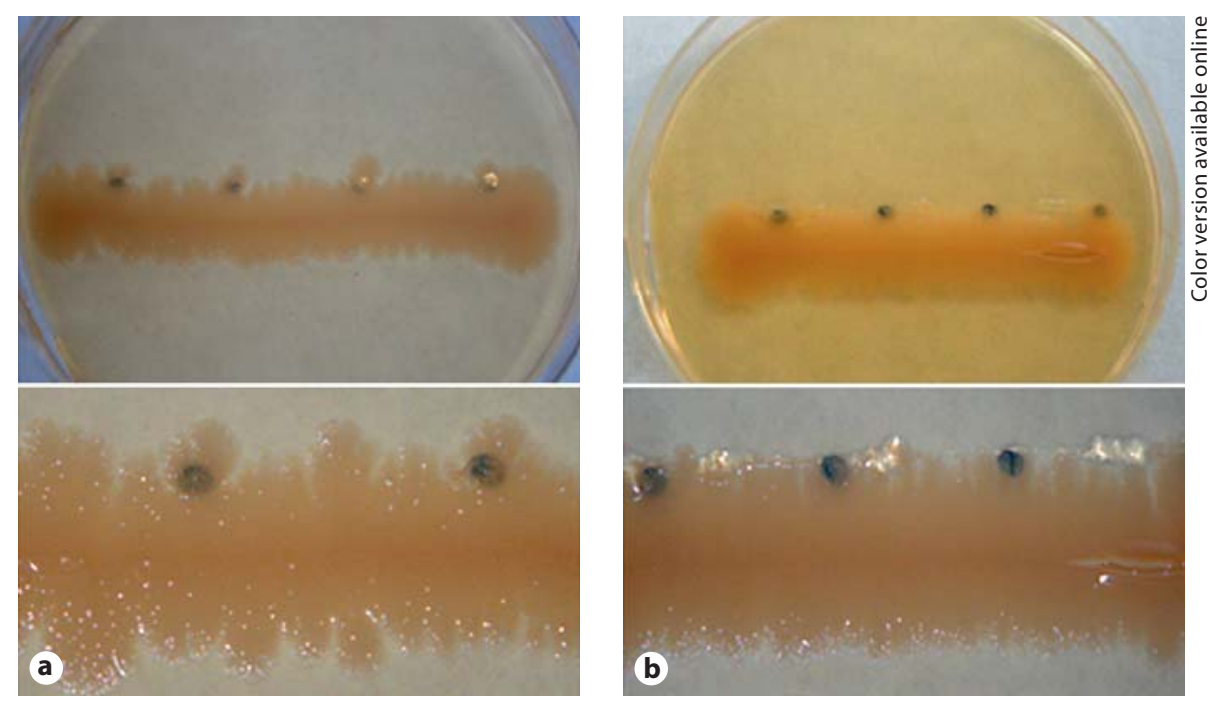

Fig. 2. Bacterial chemotaxis towards the biomaterial. a Restylane. b Bioalcamid. c Radiesse. d Aquamid. The upper photograph represents a general view of bacterial chemotaxis and the lower photograph shows it in a more detailed view.
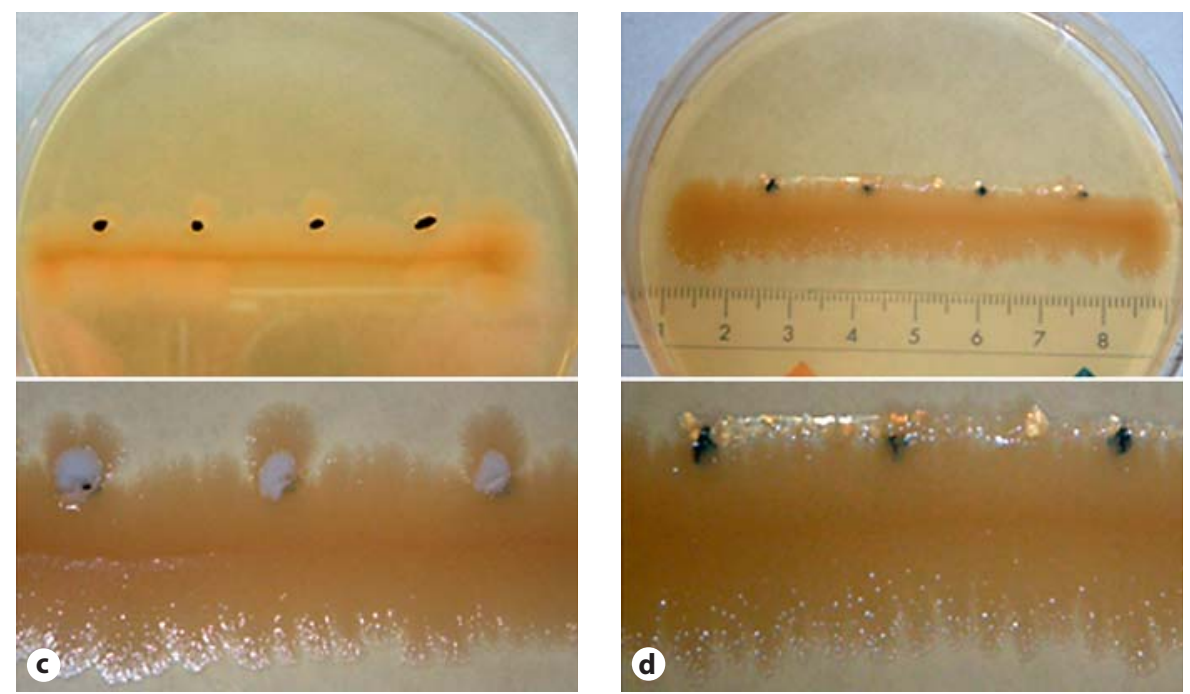

E. coli around or towards biomaterials. Nevertheless, we observed that permanent and nondegradable biomaterials, such as polyalkylimide and polyacrylamide, did not allow bacterial growth over the biomaterial itself. On the contrary, hyaluronic and hydroxylapatite compounds allowed bacterial colonization over the biomaterial. The same observations were made when performing this experiment in depth conditions. At last, when we used both a magnifying glass and an inverted microscope to observe the interface bacteria-filler, similar results were obtained (fig. 4). The four biomaterials used did not show chemoattractant activity towards bacterial growth. Slight differences in the behavior of permanent and nonpermanent fillers similar to those observed by eye were also observed.

Bacterial Infection and Late Granuloma Related to Dermal Fillers

\section{Discussion}

There is no doubt that biomaterials may provoke local or systemic chronic granulomatous immune-mediated reactions in some individuals $[1,7-9,12,16,18-22]$. The exact cause of these adverse effects is elusive. As in other granulomatous or autoimmune conditions, the relationship between microorganisms and the development of some inflammatory and autoimmune systemic diseases, such as systemic lupus erythematosus, vasculitis, sarcoidosis and atherosclerosis, is a raising issue $[9,10,15$, 17]. In the same way, an association between systemic bacterial infections and flares of the above-mentioned diseases has also been described $[1,9,11]$. However, conclusive results are lacking. In some of our patients, espe-

Dermatology 2010;221:356-364 

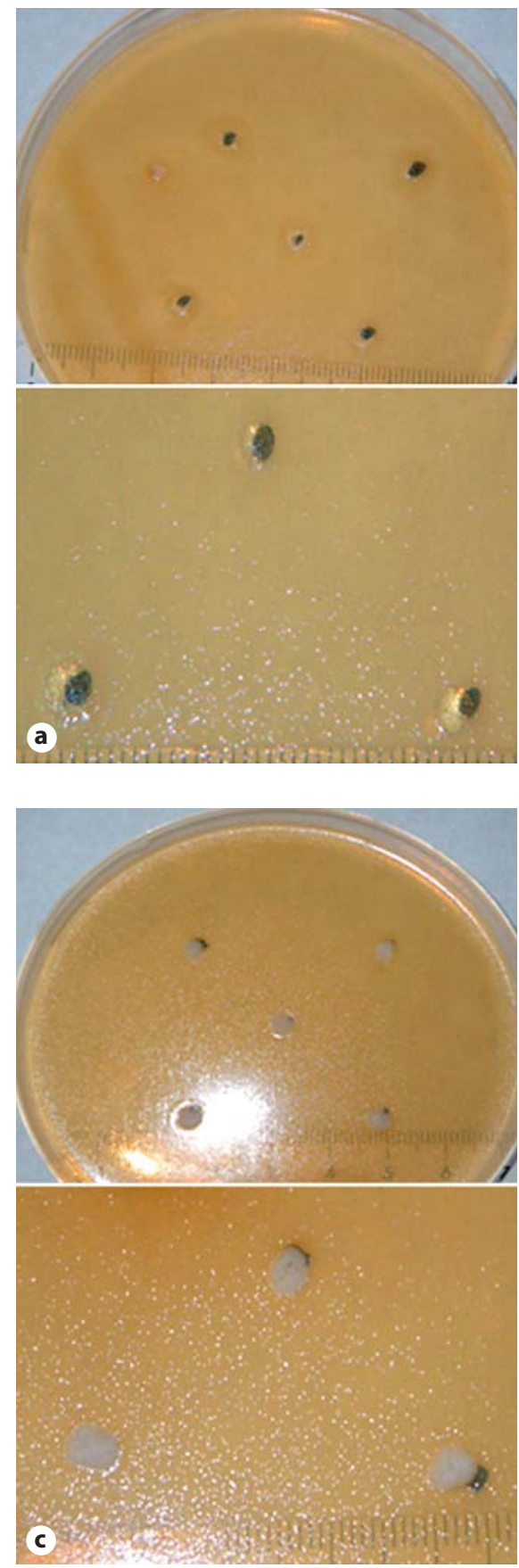
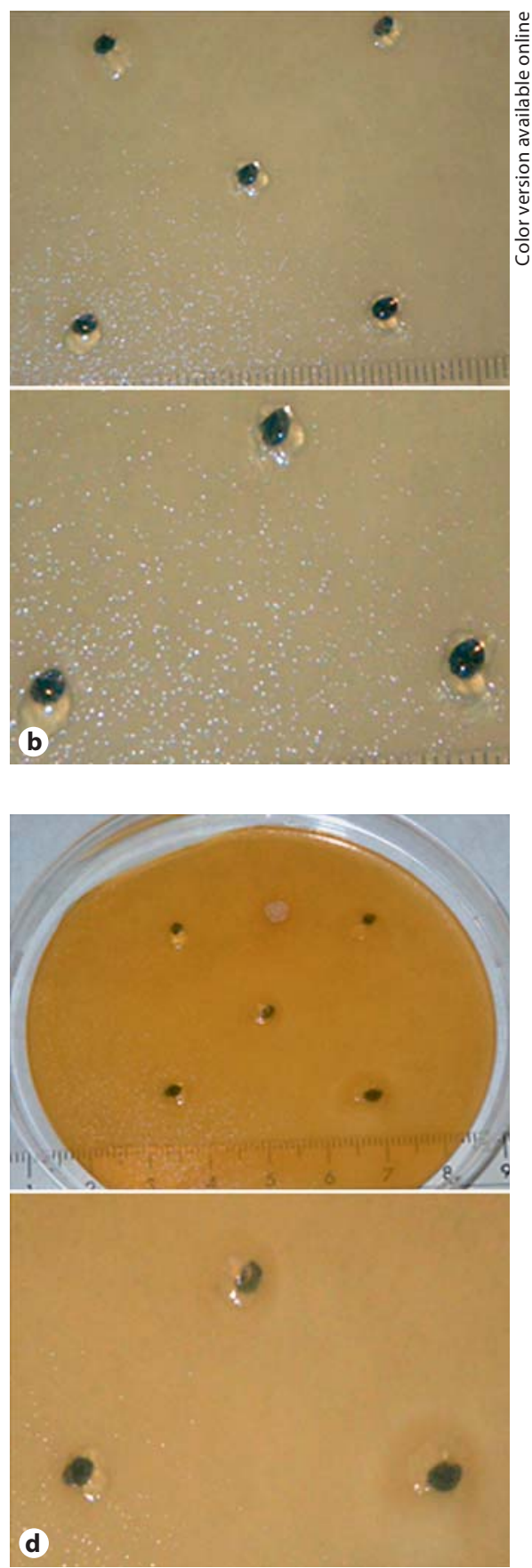

Fig. 3. Bacterial growth on the biomaterial. a Restylane. b Bioalcamid. c Radiesse. d Aquamid. The upper photograph represents a general view of bacterial growth and the lower photograph shows it in a more detailed view. cially in those injected with resorbable and semi-permanent fillers, certain bouts were related to facial traumas or previous infectious diseases $[11,18,20]$. This clinical correlation highlights the possible role of infective agents, bacteria and viruses as triggering factors for the development of pathological immune-mediated reactions [14, 25]. Christensen et al. [14] reported that local bacterial growth may cause granulomatous responses. They analyzed 28 biopsies from intermediate or late inflammatory nodules after injection of different permanent fillers, looking for evidence of bacterial presence. In some cases, a small number of bacteria were detected although some of the biopsies were negative by PCR. Interestingly, many of the recovered bacteria are not considered human 

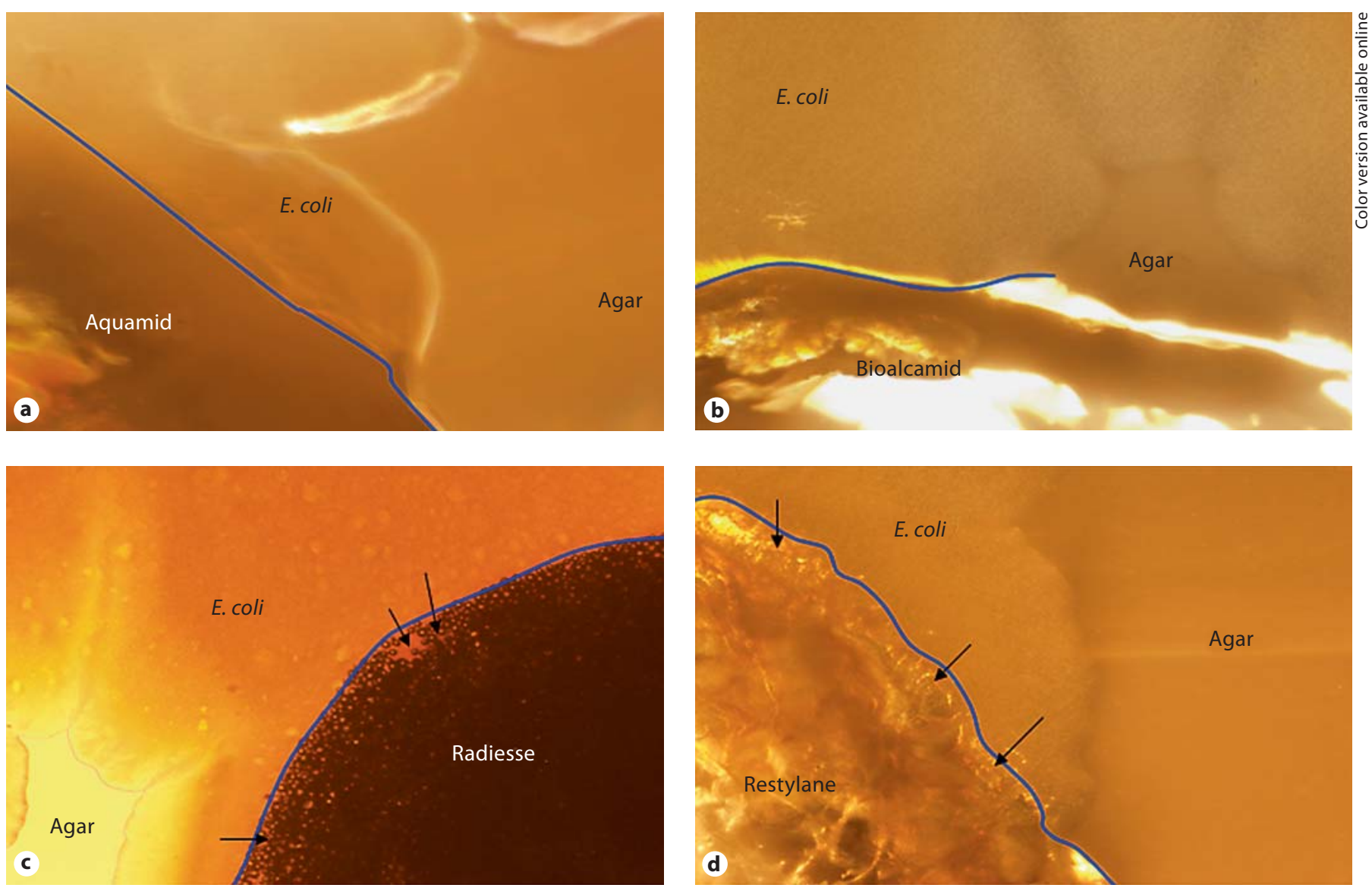

Fig. 4. Bacterial growth on the biomaterial by inverted microscopy $(\times 40)$. a, b Filler-bacteria interface (blue line), with a sharp line between them (stopping line). c, d Few bacterial colonies over the fillers (arrows). Interface also represented with a blue line.

pathogens. Other authors have also obtained bacteria from cultures of the material from drainage of inflammatory nodules [25-29]. In these reported cases, Staphylococcus aureus, Streptococcus spp. and Pseudomonas aeruginosa (1 case) were recovered from those cultures. The latter are uncommon microorganisms in the skin. Common skin bacteria include: $\mathrm{S}$. aureus, coagulase-negative Staphylcococcus spp., diphteroids, Streptococcus spp. and Propionibacterium acnes [30]. However, Enterobacteriaceae and $P$. aeruginosa may also be recovered [31]. The origin of infection of the fillers remains difficult to determine, but the potential sources of infection could be multiple: a contaminated implant, 'surgical' environment, patient skin or, as suggested by many reports, seeding of the filler from a remote infection $[31,32]$. In another report, Christensen et al. [33] discussed the pathogenic role of microorganisms in late granulomas associated with fillers, and considered that antibiotic treatment is mandatory although only 10 out their 55 cases were cured with antibiotics alone or in combination with other drugs. Thus, several authors again suggested a possible relationship between fillers and in situ bacterial infection, mainly if a biofilm is created $[14,31,33]$. Measurements of implant-induced chemotaxis and the ability to sustain bacterial growth in vitro may not explain the in vivo reality. Our experiments only aimed at demonstrating the possible in vitro ability to favor chemotaxis or the chemoattractant properties of different fillers. If the final results showed the presence of chemotaxis or bacterial overgrowth, a possible relation between filler and bacteria could be inferred. In effect, the behavior of isolated bacteria or medium bacteria could differ from that observed in biofilm. If an implant is contaminated, a biofilm consisting of bacteria and their nutrients - imper- 
meable to antibiotics - may form around it. In this manner, a chronic, low-grade infection could worsen and/or perpetuate an inflammatory granuloma. Permanent implants are associated with an increased risk of low-grade infection due to a biofilm forming around them [33].

This risk depends on the nature of the implant. Theoretically, fillers non-exchangeable with human body fluid water molecules are prone to molecular condensation and formation of a biofilm. If contaminated, the risk of infection is high and life-long. In theory, fillers with a higher water proportion and water constantly exchanged with water molecules of the surrounding tissue fluids give the gel a constant undulating movement which disturbs the integrity of the biofilm $[14,33]$. Nevertheless, this hypothesis still needs to be better demonstrated. In spite of that, antibiotics are used as a treatment of this kind of medical complications though the role of antibiotics either as anti-inflammatory or bactericidal drugs is disputable. Although we were not able to demonstrate their anti-inflammatory effect in two previous in vitro studies [21,22], other authors obtained different results. Webster et al. [34], in an elegant study, showed that tetracyclines and ciprofloxacin dose-dependently inhibited granuloma formation in vitro. However, well-designed human studies are lacking in this field. Besides, patients affected by granulomas are frequently treated with drug combinations, making it difficult to determine the true effect of each drug [35].

Our experiment was simple but rigorous. Multiple plate readings performed at different times from $24 \mathrm{~h}$ up to 10 days failed to show any kind of enhancing effect on bacterial growth or chemoattraction in all analyzed biomaterials. However, the cultures exhibited two different growth patterns, the first corresponding to permanent acrylic compounds (PA and PAI) did not present chemoattractant properties nor did they show bacterial growth over the biomaterial; the second pattern was observed with resorbable and semi-permanent fillers, i.e. hyaluronic acid and and calcium hydroxylapatite compounds. In this case, the biomaterials did not stimulate bacterial growth, but they permitted bacterial colonization over the filler. The same results were obtained for in-depth cultures. Our data partially agree with our clinical series, wherein bacteria were recovered in a few cases, and the response to antibiotics was unfavorable $[10,16$, 18]. In other experiments, we did not find increased lymphokine production, except for mainly IFN- $\gamma$ and IL-2, when human peripheral blood mononuclear cells were cultured with biomaterials in combination with bacterial lipopolysaccharide [21,22].
It is important to differentiate two possible sources of bacterial presence: (1) bacteria are directly inoculated into the filler or reach the filler from distant sites: according to our results, this scenario appears to be more problematic if the filler used is a permanent acrylic compound; (2) distant or systemic infection may provoke inflammatory harmful immune-mediated reactions to the fillers in the absence of bacterial colonization of the implant filler. Two or more different antigenic stimuli may increase the risk of abnormal immune response and may produce autoimmune-mediated adverse effects [36]. In this context, our previous results agree with the fact that fillers may induce proinflammatory cytokines by human monocytes, and could therefore potentially trigger inflammation or exacerbate preexisting inflammatory processes $[21,22]$.

Microbial agents can induce immune-mediated diseases by a variety of mechanisms $[15-17,25,27,37]$. The contribution of toll-like receptors (TLRs) in this context has recently been identified, improving our understanding of this fact. The initiation of inflammation may occur not only with lipopolysaccharides and peptidoglycans but also with other microbial products such as polysaccharides, enzymes and toxins. Bacterial flagellae activate inflammation by binding TLR5. Bacteria also produce high amounts of DNA molecules with unmethylated CpG residues that activate inflammation through TLR7 and TLR9. Some acylated microbial proteins may activate innate immunity by TLR1 and TLR6 recognition. TLR expression in several different cell types and the active cross-talk that antigen-presenting cells and B cells display with $T$ cells may explain why these receptors are now accepted as a link between adaptive and innate immunity $[38,39]$.

In our study, bacteria grew uniformly in plates, and we did not observe bacterial clusters around the different biomaterial spots. The different behavior of permanent and resorbable and semi-permanent fillers may be explained by the organic characteristics of proteoglycans such as hyaluronic acid. These compounds serve as an extracellular matrix and permit the bacterial diffusion but not overgrowth. Further, a similar behavior has been observed with calcium hydroxylapatite microspheres. calcium hydroxylapatite dermal filler is made from a biocompatible substance that is identical to a substance naturally found in the body. It serves as an extracellular matrix for bone tissues. We can conclude that it was not possible to demonstrate that permanent resorbable and semi-permanent fillers facilitate bacterial growth when flagellated E. coli was used. Permanent implant fillers 
do not seem to facilitate bacterial growth over and/or through filler spots. Consequently, the pathogenic role played by bacteria, as direct in situ infective agents is questionable. Our study, however, has two limitations. First, we have only analyzed capability of the filler to favor growth and/or chemotaxis only using the flagellated bacteria $E$. coli because of its mobility. It could be discussed whether the results might have been different if we had used bacteria more commonly found in the skin, such as S. aureus or Streptococcus spp. Second, we have not studied the interactions between bacteria and fillers in a biofilm interface. This may be a different pathological situation that could be studied in the future although not all fillers seem to build a biofilm. Otherwise, the behavior of fillers depends on their water contents and their ability to be exchanged with water surrounding molecules.

Finally, according to our results, there is no evidence arguing in favor of antibiotic use as the mainstay of therapy in late granulomas related to permanent implant fillers. More studies on the role played by bacterial infec- tions associated with both resorbable and semi-permanent compounds are needed. The possible role antibiotics may play is unclear and their role as immunomodulating agents in different granulomatous disorders, including those related to late reactions to dermal fillers, still needs to be extensively studied.

\section{Acknowledgments}

We thank Simo Schwartz Jr., Guillem Prats and Iliana Acosta for laboratory assistance and scientific advice. We would also like to acknowledge the Sociedad Española de Medicina y Cirugía Cosmética (SEMCC) for partial support and all of its members for their kind collaboration.

\section{Disclosure Statement}

All authors state that they do not have any commercial or other interest that might have influenced the drawing up and the results of this paper.

\section{References}

1 De Boulle K: Management of complications after implantation of fillers. J Cosmet Dermatol 2004;3:2-15.

2 Ellis DA, Makdessian AS, Brown DJ: Survey of future injectables. Facial Plast Surg Clin North Am 2001;9:405-411.

3 Castillo-Vico MT, Checa-Vizcaino MA, Pava-Panades A: Periurethral granuloma following injection with dextranomer/hyaluronic acid copolymer for stress urinary incontinence. Int Urogynecol J Pelvic Floor Dysfunct 207;18:95-97.

-4 Bernauer W, Thiel MA, Kurrer M, et al: Corneal calcification following intensified treatment with sodium hyaluronate artificial tears. Br J Ophthalmol 2006;90:385-388.

5 Frank PJ: Cosmetic symposium: Restylane. The Dermatologic Society of Greater New York. Available at: http://www.dersociety. org $/$ default. asp?id=3\&aui=sa\&aid=35 (accessed February 2, 2005).

-6 Engelman DE, Bradley B, Glodberg DJ: Dermal fillers: complications and informed consent. J Cosmet Laser Ther 2005;7:29-32.

$\checkmark 7$ Duffy DM: Complications of fillers: overview. Dermatol Surg 2005;31:1626-1633.

$\checkmark 8$ Bergeret-Galley C: Comparison of resorbable soft-tissue fillers. Aesthetic Surg J 2004; 24:33-46.

$\$ 9$ Cohen JL: Understanding, avoiding, and managing dermal filler complications. Dermatol Surg 2008;34(suppl):S92-S99.
10 Cristal RG: Sarcoidosis; in: Kasper DL, et al (eds). Harrison's Principles of Internal Medicine, ed 16. New York, McGraw-Hill, 2005, pp 2017-2023.

11 James DG: Sarcoidosis 2001. Postgrad Med J 2001;77:177-180.

12 Alijotas-Reig J, Garcia-Gimenez V: Delayed immune-mediated adverse effects related to hyaluronic acid and acrylic hydrogel dermal fillers: clinical findings, long-term follow-up and review of the literature. J Eur Acad Dermatol Venereol 2008;22:150-161.

13 Christensen L: Normal and pathologic tissue reactions to soft tissue gel fillers. Dermatol Surg 2007;33(suppl 2):S168-S175.

14 Christensen L, Breiting V, Janssen M, et al: Adverse reactions to injectable soft tissue permanent fillers. Aesthetic Plast Surg 2005; 29:34-48.

15 Blank M, Krause I, Fridkin M, et al: Bacterial induction of autoantibodies to $\beta_{2}$-glycoprotein-I accounts for the infectious etiology of antiphospholipid syndrome. J Clin Invest 2002;109:797-804.

16 Getts MT, Miller SD: 99th Dahlem Conference on Infection, Inflammation and Chronic Inflammatory Disorders: triggering of autoimmune diseases by infections. Clin Exp mmunol 2010;160:15-21.

17 Albert LJ, Inman RD: Molecular mimicry and autoimmunity. N Engl J Med 1999;341: 2068-2074.
18 Alijotas-Reig J, Garcia-Gimenez V, MiróMur F, Vilardell-Tarrés M: Delayed immune-mediated adverse effects related to polyalkylimide dermal fillers: clinical findings and follow-up. Arch Dermatol 2008; 144: 637-642.

19 Alijotas-Reig J: Recurrent urticarial vasculitis related to nonanimal hyaluronic acid skin filler injection. Dermatol Surg 2009;35:395398.

20 Alijotas-Reig J, Garcia-Gimenez V, MiróMur F, Vilardell-Tarrés M: Delayed immune-mediated adverse effects related to polyacrylamide dermal fillers: clinical findings, management, and follow-up. Dermatol Surg 2009;35:360-366.

21 Miró-Mur F, Hindié M, Kandhaya-Pillai R, et al: Medical-grade silicone induces release of proinflammatory cytokines in peripheral blood mononuclear cells without activating T cells. J Biomed Res B Appl Biomater 2009; 90:510-520.

22 Alijotas-Reig J, Miró-Mur F, Kandhaya-Pillai R, Schwartz S Jr: Bioengineered hyaluronic acid elicited a nonantigenic T-cell activation: implications from cosmetic medicine and surgery to nanomedicne. J Biomed Mater Res A 2010;95:180-190.

23 Le Minor L: Entérobacteries, éd 3. SaintMandé, Editions de la Tourelle, 1969.

24 Murray PR, Barm EJ, Jorgensen JH (eds): Manual of Clinical Microbiology, ed 9. Washington, ASM Press, 2007. 
$>25$ Christen U, von Herrath G: Infections and autoimmunity. Good or bad? J Immunol 2005;174:7481-7486.

-26 Serrano C, Serrano S: Infección demorada tras el uso de Bio-Alcamid. Actas Dermosifiliogr 2006;97:460-462.

$>27$ Goldan O, Georgiou I, Farber N, et al: Lateonset facial abscess formation after cosmetic soft tissue augmentation with Bio-Alcamid. Aesthetic Surg J 2007;27:416-418.

$\checkmark 28$ Goldan O, Georgiou I, Grabov-Nardini G, et al: Early and late complications after a nonabsorbable hydrogel polymer injection: a series of 14 patients and novel management. Dermatol Surg 2007;33:S199-S206.

-29 Jones DH, Carruthers A, Fitzgerald R, et al: Late-appearing abscesses after injections of nonabsorbable hydrogel polymer for HIVassociated facial lipoatrophy. Dermatol Surg 2007;33:S193-S198.
30 Serrano-Grau P, Mascaró-Galy JM, Tranzo $\mathrm{P}$, et al: Productos de relleno inyectables en dermocosmética. Tipos y efectos secundarios. Med Cutan Iber Lat Am 2007;35:209218.

31 Pittet B, Montandon D, Pittet D: Infection in breast implants. Lancet Infect Dis 2005;5: 94-106.

\$2 Brand KG: Infection of mammary prostheses: a survey and the question of prevention. Ann Plast Surg 1993;30:289-295.

33 Christensen LH, Breiting VB, Vuust J, et al: Adverse reactions following injections with permanent facial filler, polycrylamide hydrogel (Aquamid): causes and treatment. Eur J Plast Surg 2006;28:464-471.

34 Webster GF, Toso SM, Hegemann L: Inhibition of a model of in vitro granuloma formation by tetracyclines and ciprofloxacin. Involvement of protein kinase C. Arch Dermatol 1994;130:748-752.
35 Chrastil-LaTowsky B, Wesley NO, MacGregor JL, et al: Delayed inflammatory reaction to Bio-Alcamid polyacrylamide gel used for soft tissue augmentations. Arch Dermatol 2009; 145:1309-1312.

36 Arbuckle MR, McClain MT, Rubertone MV, et al: Development of autoantibodies before the clinical onset of systemic lupus erythematosus. N Engl J Med 2003;349:1526-1533.

37 Wucherpfennig KW: Mechanisms for the induction of autoimmunity by infectious agents. J Clin Invest 2001;108:1097-1104.

38 Rsachi E, Borghi MO, Grossi C, et al: Tolllike receptors: another player in the pathogenesis of the anti-phospholipid syndrome. Lupus 2008;17:937-942.

39 Chen K, Huang J, Gong W, et al: Toll-like receptors in inflammation, infection and cancer. Int Immunopharmacol 2007;7:12711285 